\title{
Transforming Olefins into Dinucleophiles
}

\author{
Andrés García-Domínguez ${ }^{\S}$ and Cristina Nevado* \\ §SCS-Metrohm Award for best oral presentation in Organic Chemistry
}

\begin{abstract}
Herein we present the first example of a three-component dicarbofunctionalization of olefins under reductive conditions. Our strategy takes advantage of nickel catalysis to add aryl and alkyl groups across the double bond with remarkable selectivity. The reaction shows broad functional group compatibility and more importantly, it proves to be general in terms of the alkenes that can be functionalized compared to previous dicarbofunctionalization methods. Initial control experiments reveal different activation modes for both electrophiles and the involvement of alkyl radicals throughout the reaction.
\end{abstract}

Keywords: Cross-coupling · Dicarbofunctionalization · Nickel catalysis · TDAE

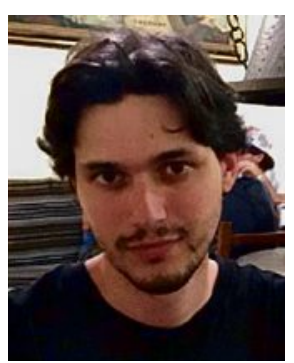

Andrés García Domínguez obtained his BSc in Chemistry from Universidad Autónoma de Madrid (Spain) in 2011. In 2013, he received his MSc in Organic Chemistry from the same university under the supervision of Prof. Dr. Diego J. Cárdenas and moved to University of Zurich (Switzerland) to carry out his $\mathrm{PhD}$ under the supervision of Prof. Dr. Cristina Nevado. His research interests are currently focused on the development of new transition metal-catalyzed methods for carbofunctionalizations of multiple bonds involving radical mechanisms. As recognition of his performance, he received the Albert Hoffman PhD award for Excellence in Research in 2017.

\footnotetext{
${ }^{\star}$ Correspondence: Prof. Dr. C. Nevado Department of Chemistry, University of Zurich Winterthurerstrasse 190, CH-8057 Zurich E-mail: cristina.nevado@chem.uzh.ch
}

Olefins are present in naturally occurring chemicals as well as in pharmaceuticals, thus making them attractive targets for late-stage modifications. In addition, alkenes can be prepared by well-established methods at an industrial scale, thus being cost-effective substrates for organic and organometallic reactions. Among the different transformations they can undergo, difunctionalization reactions play a prominent role as they enable the simultaneous formation of two vicinal $\mathrm{Csp}^{3}-\mathrm{X}$ bonds. ${ }^{11]}$ In this context, metal-catalyzed threecomponent alkene dicarbofunctionalizations have recently gained attention due to their convergence and intrinsic ability to create up to two stereogenic centers and therefore, their potential to rapidly generate more complex aliphatic structures.

Conventional strategies towards alkene dicarbofunctionalization take advantage of redox neutral conditions and therefore rely formally on the use of a nucleophile and an electrophile as carbon sources (Scheme 1, top). In this manner, both carbon partners offer complementary reactivity towards the metal catalyst, which translates into a highly regioselective process. The major challenge in these transformations has to do with the sensitivity of the putative alkyl-metal intermediates involved, which can decompose via $\beta$-hydride elimination and produce undesired products. ${ }^{[2]}$ Using palladium catalysis, dienes ${ }^{[3]}$ or olefins containing directing groups ${ }^{[4]}$ have been efficiently engaged in this type of process as they generate allyl$\mathrm{Pd}$ intermediates and rigid five-membered palladacycles, respectively (Scheme 1, top left). These complexes are less prone to $\beta$-hydride elimination compared to simple alkyl-palladium species, aiding the success of the overall process. Unfortunately, these reactions are not only limited to this specific type of olefins, but are also restricted to the formation of two $\mathrm{Csp}^{3}-\mathrm{Csp}^{2}$ bonds.
Nickel catalysis has also been explored in dicarbofunctionalization processes. The slower rate of decomposition of alkyl-nickel species via $\beta$-hydride elimination compared to palladium species has enabled the incorporation of aliphatic groups in these transformations. ${ }^{[5]}$ However, despite its potential, only acrylates ${ }^{[6]}$ and vinyl amides $^{[7]}$ have been successfully engaged in alkylative difunctionalization processes (Scheme 1, top right). ${ }^{[8]}$ Thus, redox neutral strategies are restricted to the use of a few tailored olefins, which makes the development of alternative and more general approaches a worthwhile endeavor.

Given our interest in the efficient carbofunctionalization of $\pi$-systems ${ }^{[9]}$ and the potential of nickel in cross-electrophile coupling reactions, ${ }^{[10]}$ we envisioned the possibility of a reductive dicarbofunctionalization to overcome these limitations. In our design, two electrophiles would be added across the double bond in the presence of an external reductant which could translate into milder reaction conditions and broader functional group compatibilities. Here, we present the realization of this approach which has proven general in terms of the olefinic partners able to participate in these transformations (Scheme 1, bottom). ${ }^{[11]}$

After initial optimization efforts, we found that tertiary aliphatic groups and arenes can be added onto olefins with complete regioselectivity starting from the corresponding iodides (Scheme 2). Remarkably, side products stemming from reactions between the two electrophilic components were not detected in the reaction media. The process is carried out under mild conditions using a combination of an air- and moisture-stable nickel precatalyst, 4,4'-di-tert-butyl-2,2'bipyridine (dtbbpy) and an organic reductant (tetrakis(dimethylamino)ethyl- 
ene $=$ TDAE) ${ }^{[12]}$ Both electron-rich and electron-deficient alkenes tested in previous methodologies delivered the desired products $\mathbf{1}$ and $\mathbf{2}$ in 65 and $92 \%$ yield, respectively. Internal olefins such as crotonitrile $(E: Z=4: 1)$ could also participate in the reaction furnishing product 3 with moderate efficiency but with high diastereoselectivity. To our delight, the generality of this approach could be demonstrated by its application to unactivated olefins containing different groups at the allylic position (4-6). Unfortunately, unfunctionalized olefins did not engage under these reaction conditions, thus suggesting the need for a weakly coordinating/activating moiety in the substrate. In terms of the aromatic partner, the reaction displayed broad scope encompassing different electronics and substitution patterns, although substrates containing ortho-substituents gave the desired products in low yields (7). Remarkably, other $\mathrm{Csp}^{2}$-halogen bonds as well as $\mathrm{Csp}^{2}-\mathrm{B}$ bonds remained unreacted under the reaction conditions $(\mathbf{8}-\mathbf{1 0})$, highlighting the high chemoselectivity for $\mathrm{Csp}^{2}-\mathrm{I}$ bonds and the orthogonality of this method with respect to classical cross-coupling procedures. Finally, differently functionalized tertiary alkyl groups also led to the desired products 11-13, thus providing more complex aliphatic structures in a single step.

Several control experiments were performed to investigate the mechanism of this transformation. Initially, the addition of radical traps and inhibitors such as BHT, 1,1-diphenylethylene and 1,4-cyclohexadiene led to decreased yields of the product suggesting the possibility of radical intermediates along the reaction pathway (data not shown). Competitive radical clock experiments using 6-iodo-6-methylhept-1-ene (14) in the presence of an external olefin and the arene partner were performed (Scheme 3A). While with allyl acetate the cyclization of the alkyl iodide is favored over the intermolecular addition to the double bond to give $\mathbf{1 5}$, the reaction in the presence of acrylonitrile delivered the three-component adduct $\mathbf{1 6}$ in $45 \%$ yield and no carbocyclization was observed. These results are in agreement with previously kinetic data reported for related radical processes, ${ }^{[13]}$ which support the formation of $C$-centered radicals in the reaction media. Since this type of radicals are being generated from the aliphatic iodide, the final products could be the result of a twostep process in which alkyl iodides might have been formed by an iodine transfer radical addition reaction. ${ }^{[14]}$ However, different secondary iodides submitted to the reaction conditions proved to be incompetent for a cross-electrophile coupling with the aryl iodide (Scheme 3B). Hence, the presence of secondary aliphatic iodides as

Conventional approach: Limited to tailored olefins

$$
\mathrm{O}+\mathrm{C}-\mathrm{M}+\mathrm{c}-\mathrm{x}-\mathrm{IM]} \rightarrow \mathrm{C}_{\mathrm{C}}
$$

Pd-catalyzed reactions (Only Csp ${ }^{2}$ coupling partners)

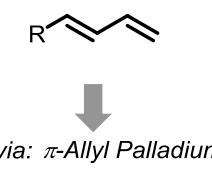<smiles>C=CCC(=O)Nc1cccc2cccnc12</smiles>

via: $\pi$-Allyl Palladium via: Palladacycle C

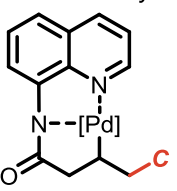

Ni-catalyzed reactions

Alkylative strategies (Electronically activated substrates)<smiles>C=CC(=O)OBr</smiles><smiles>C=CN1CCCC1=O</smiles>

via: Radical Addition

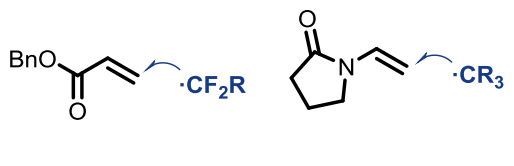

Reductive dicarbofunctionalization (this work): A unifying approach

$$
\mathrm{O}+\underset{\text { 'Electrophile' 'Electrophile' [Reductant] }}{[\mathrm{Ni}]} \rightarrow \mathrm{Ar}+\mathrm{Alkyl}-\mathrm{x}-\mathrm{Alkyl}_{\mathrm{A}}
$$

\section{General in olefin}

$$
\text { Electronrich Electrondeficient Unactivated }
$$

Alkylative

Multicomponent

Highly selective

Mild conditions

- Good FG tolerance

Scheme 1. Strategies for metal-catalyzed vicinal dicarbofunctionalization of olefins.

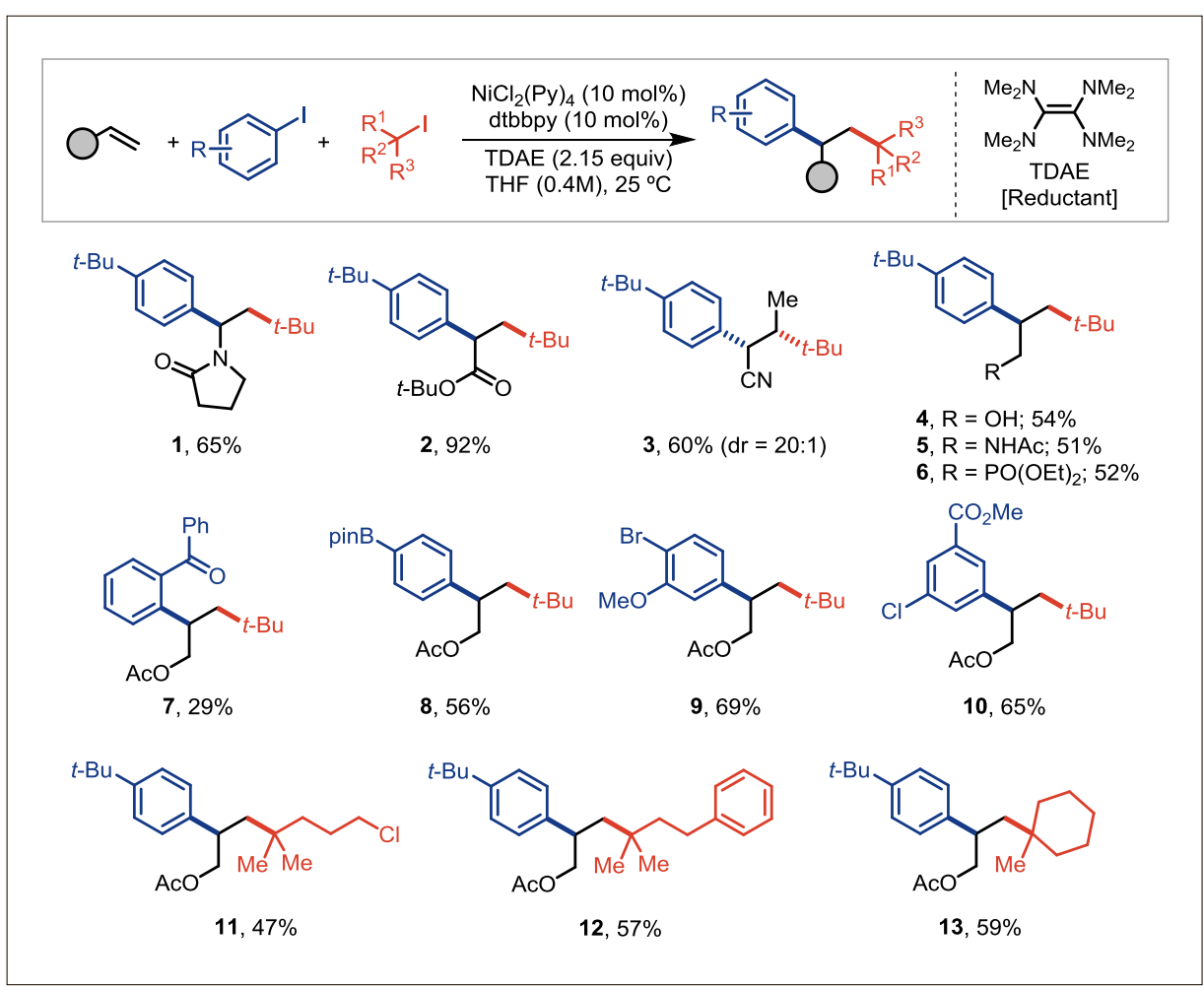

Scheme 2. Reductive three-component alkene dicarbofunctionalization: selected scope.

putative intermediates in this process can be ruled out.

The presence of different organonickel species and the role of the reductant were investigated next (Scheme 4). $\mathrm{Ni}(0)$ species could be potential intermediates since they readily reacted with aromatic iodides to deliver aryl-Ni(II) complex 18. 


\section{A) Competitive radical clock experiments}

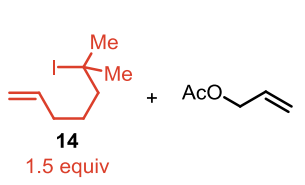

$\mathrm{NiCl}_{2}(\mathrm{Py})_{4}(10 \mathrm{~mol} \%)$ L1 (10 mol\%)
TDAE (2.0 equiv) Ar-l $(2.0$ equiv)
$\operatorname{THF}(0.4 \mathrm{M}), 25^{\circ} \mathrm{C}$

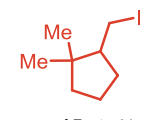

$15,17 \%$
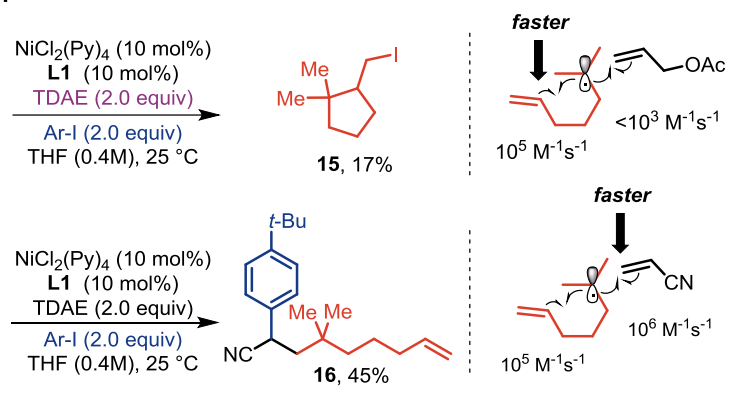

$10^{5} \mathrm{M}^{-1} \mathrm{~s}^{-1}$

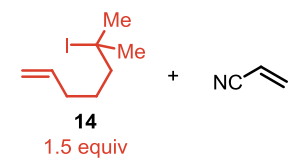

B) Cross-electrophile coupling using secondary iodides
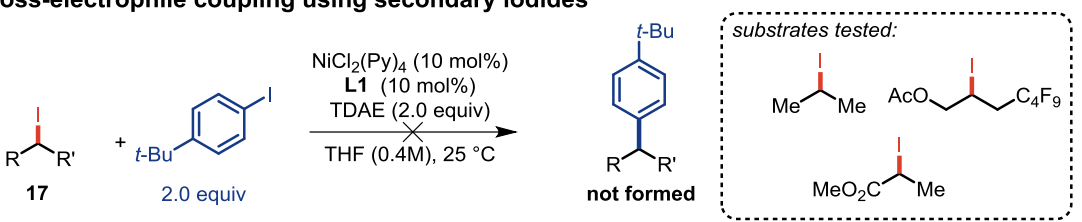

Scheme 3. Radical clock experiments and competence of secondary alkyl iodides.

\section{A) Formation of [Ar-Ni(II)] complexes}
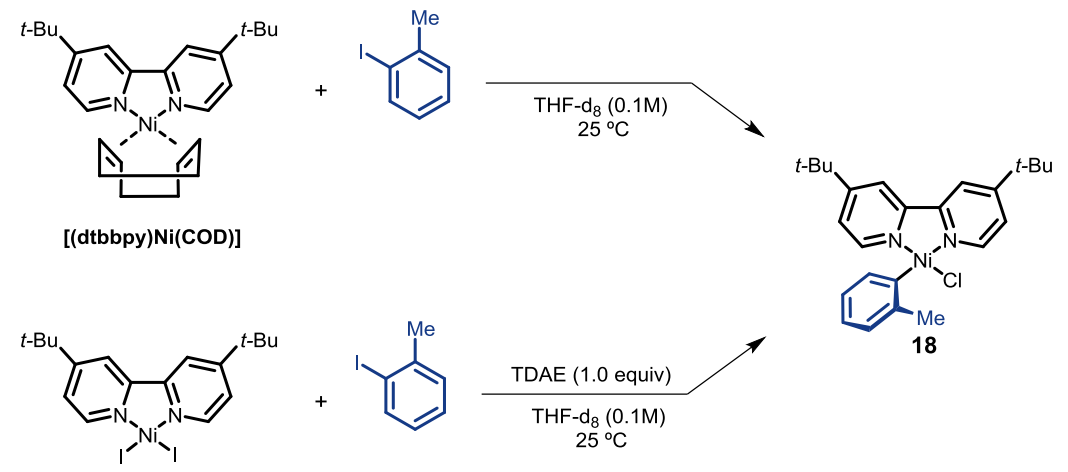

[(dtbbpy) $\mathrm{Nil}_{2}$ ]

B) Competence of $[\mathrm{Ar}-\mathrm{Ni}(\mathrm{II})]$ complexes
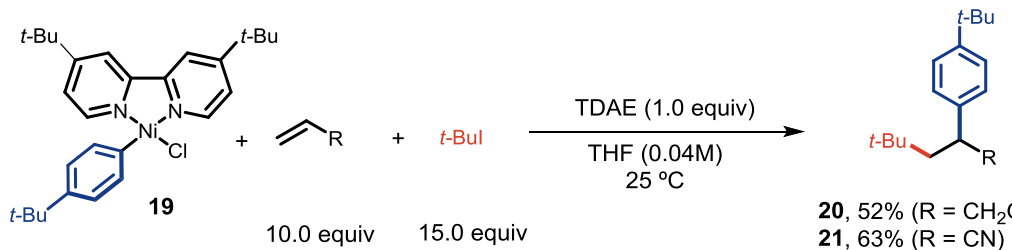

20,52\% $\left(\mathrm{R}=\mathrm{CH}_{2} \mathrm{OAC}\right)$ $21,63 \%(\mathrm{R}=\mathrm{CN})$

Scheme 4. Stoichiometric control experiments involving nickel complexes.

Additionally, the latter can also be accessed by the reaction of [(dtbbpy) $\left.\mathrm{NiI}_{2}\right]$ with an equimolar amount of TDAE and aryl iodide, demonstrating the ability of TDAE to reduce Ni(II) species (Scheme 4A). Interestingly, the stoichiometric reaction of the aryl-Ni(II) complex 19 with the olefin and tert-butyl iodide in the presence of TDAE furnished the desired products, thus proving the competence of aryl-Ni(II) as putative intermediates in these transformations (Scheme 4B).

Based on the above-mentioned control experiments, the following mechanism can be proposed (Scheme 5). Under the reduc- tive conditions, $\mathrm{Ni}(0)$ species generated in situ can participate in an oxidative addition with the Ar-I to give Ar-Ni(II) intermediate $\mathbf{A}$. In parallel, Ni(I) species produced in the reaction media could activate the aliphatic iodide to produce radical $\mathbf{C}$, which delivers intermediate $\mathbf{D}$ by regioselective addition to the terminal carbon of the olefin. These species combine with A to produce the key organonickel(III) complex B, which after reductive elimination, forms the corresponding dicarbofunctionalization product while regenerating $\mathrm{Ni}(\mathrm{I})$. As shown before, $\mathrm{Ni}(\mathrm{I})$ reacts with the alkyl iodide forming as a result $\mathrm{Ni}$ (II) complexes which are subsequently reduced to $\mathrm{Ni}(0)$ by TDAE closing the entire catalytic cycle (path I) ${ }^{[15]}$ In situ formation of secondary alkyl iodides $\mathbf{E}$ (path II) by means of an iodine atom transfer radical addition reaction has been discarded based on their inability to furnish the coupling product with the aromatic iodides under the reaction conditions. Also, the participation of Ar-Ni(III)alkyl complexes resulting from the direct recombination of tertiary radical $\mathbf{C}$ with $\mathbf{A}$ has been ruled out as no direct aryl-alkyl product between electrophiles has been detected in the reaction media. Alternatively, a mechanism involving radical addition of D to $\mathrm{Ni}(0)$ followed by oxidative addition of the aryl iodide to deliver $\mathbf{B}$ cannot be ruled out. ${ }^{[16]}$

In summary, we present here the first example of a three-component reductive dicarbofunctionalization of alkenes. The process enables the formation of two new $\mathrm{Csp}^{3}-\mathrm{Csp}^{3}$ and $\mathrm{Csp}^{3}-\mathrm{Csp}^{2}$ bonds by sequential addition of alkyl and aryl groups, respectively, onto the alkene. Using an organic reductant under very mild reaction conditions, broad functional group tolerance has been achieved. More importantly, this approach has demonstrated useful to functionalize a wide variety of terminal olefins proving to be more general than previously existing methods. The present approach is fully regio- and chemoselective due the fact that the aromatic iodide and the aliphatic iodide are activated by different pathways. Further studies are currently ongoing in our laboratory to deeply understand the mechanism of this transformation and broaden its applicability.

Received: February 1, 2018

[1] For related reviews, see: a) H. C. Kolb, M. S. VanNieuwenhze, K. B. Sharpless, Chem Rev. 1994, 94, 2483; b) K. H. Jensen, M. S. Sigman, Org. Biomol. Chem. 2008, 6, 4083; c) H. Egami, M. Sodeoka, Angew. Chem. Int. Ed. 2014, 53, 8294; d) A. J. Crosswell, S. T.-C. Eey, S. E. Denmark, Angew. Chem. Int. Ed. 2015, 54, 15642; e) T. Courant, G. Masson, J. Org. Chem. 2016, 81, 6945; f) B. Ovadia, F. Robert, Y. Landais, Chimia 2016, 70, 34; g) X.-W. Lan, N.-X. Wang, Y. Xing, Eur. J. Org. Chem. 2017, 5821.

[2] X. Lu, Top. Catal. 2005, 35, 73.

[3] a) K. B. Urkalan, M. S. Sigman, Angew. Chem. Int. Ed. 2009, 48, 3146; b) L. Liao, R. Jana, K. B. Urkalan, M. S. Sigman, J. Am. Chem. Soc. 2011, 133, 5784; c) M. S. McCammant, L. Liao, M. S. Sigman, J. Am. Chem. Soc. 2013, 135, 4167; d) J. B. Stokes, L. Liao, A. M. de Andrade, Q. Wang, M. S. Sigman, Org. Lett. 2014, 16, 4666; e) X. Wu, H.-C. Lin, M.-L. Li, L.-L. Li, Z.-Y. Han, L.-Z. Gong, J. Am. Chem. Soc. 2015, 137, 13476.

[4] Z. Liu, T. Zeng, K. S. Yang, K. M. Engle, J. Am. Chem. Soc. 2016, 138, 15122.

[5] For selected reviews in cross-couplings involving alkyl halides, see: a) X. Hu, Chem. Sci. 2011, 2, 1867; b) T. Iwasaki, N. Kambee, Top. 


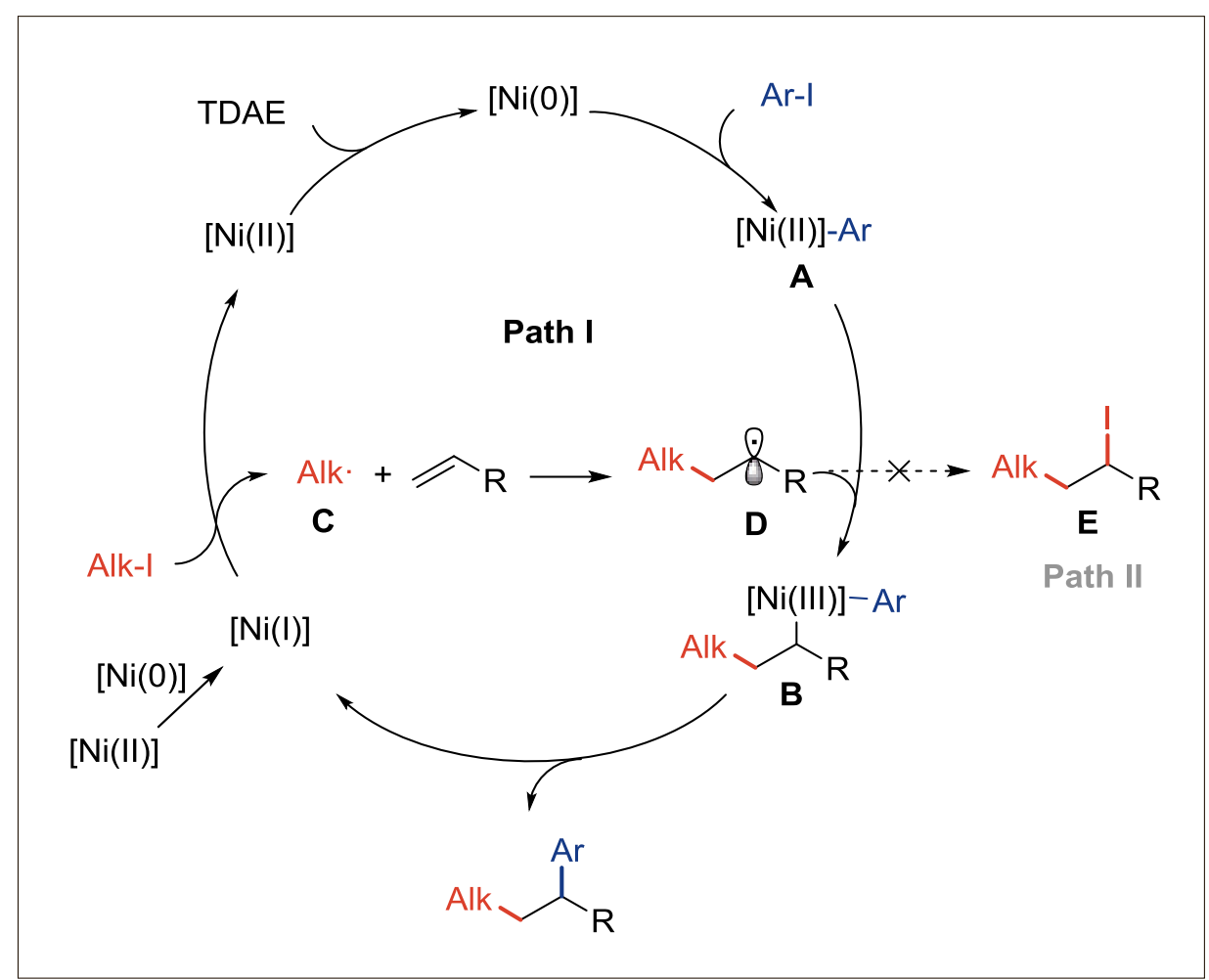

Scheme 5. Reductive three-component alkene dicarbofunctionalization: proposed mechanism.

Curr. Chem. 2016, 374, 1; c) G. C. Fu, ACS Cent. Sci. 2017, 3, 692.

[6] T. Qin, J. Cornella, C. Li, L. R. Malins, J. T. Edwards, S. Kawamura, B. D. Maxwell, M. D. Eastgate, P. S. Baran, Science 2016, 352, 801.

[7] J.-W. Gu, Q.-Q. Min, L.-C. Yu, X. Zhang, Angew. Chem. Int. Ed. 2016, 55, 12270.

[8] For other three-component vicinal alkene dicarbofunctionalzations catalyzed by nickel, see: a) J. Terao, F. Bando, N. Kambe, Chem Commun. 2009, 7336; b) B. Shrestha, P. Basnet, R. K. Dhungana, S. KC, S. Thapa, J. M.Sears, R. Giri, J. Am. Chem. Soc. 2017, 139, 10653; c) J. Derosa, V. T. Tran, M. N. Boulous, J. S Chen, K. M. Engle, J. Am. Chem. Soc. 2017, 139, 10657; d) S. Thapa, R. K. Dhungana, R. T. Magar, B. Shrestha, K. C. Shekhar, R. Giri, Chem. Sci. 2018, 9, 904; e) X.-G. Jia, P. Guo, J.
Duan, X.-Z. Shu, Chem. Sci. 2018, 9, 64. For transformations catalyzed by other first-row transition metals, see: f) F. Wang, D. Wang, X. $\mathrm{Mu}$, P. Chen, G. Liu, J. Am. Chem. Soc. 2014, 136, 10202; g) X.-H. Ouyang, R.-J. Song, M. Hu, Y. Yang, J.-H. Li, Angew. Chem. Int. Ed. 2016, 55, 3187. h) L. Wu, F. Wang, X. Wan, D. Wang, P. Chen, G. Liu, J. Am. Chem. Soc. 2017, 39, 2904;

[9] a) N. Fuentes, W. Kong, L. Fernández-Sánchez, E. Merino, C. Nevado, J. Am. Chem. Soc. 2015, 137, 964; b) Z. Li, A. García-Domínguez, C. Nevado, J. Am. Chem. Soc. 2015, 137, 11610; c) Z. Li, A. García-Domínguez, C. Nevado, Angew. Chem Int. Ed. 2016, 55, 6938; d) P. García-Domínguez, L. Fehr, G. Rusconi, Chem. Sci. 2016, 7, 3914; e) W. Shu, A. Lorente, E. Gómez-Bengoa, C. Nevado, Nature Commun.
2017, 8, 13832; f) A. García-Domínguez, S. Müller, C. Nevado, Angew. Chem. Int. Ed. 2017 , 56, 9949.

[10] For selected reviews on Ni-catalyzed reductive couplings, see: a) T. Moragas, A. Correa, R. Martin, Chem. Eur. J. 2014, 20, 8242; b) C. E. I. Knappke, S. Grupe, D. Gärtner, M Corpet, C. Gosmini, A. Jacobi von Wangelin, Chem. Eur. J. 2014, 20, 6828; c) D. J. Weix Acc. Chem. Res. 2015, 48, 1767; d) J. Gu, X. Wang, W. Xue, H. Gong, Org. Chem. Front. 2015, 2, 1411. For examples of reductive alkylarylations in an intramolecular fashion, see: e) X. Wang, S. Wang, W. Xue, H. Gong, J. Am. Chem. Soc. 2015, 137, 11562; f) Y. Peng, J. Xiao, X.-B. Xu, S.-M. Duan, L. Ren, Y.-L. Shao, Y.-W. Wang, Org. Lett. 2016, 18, 5170; g) Y. Peng, X.-B. Xu, J. Xiao, Y.-W. Wang, Chem Commun. 2014 50, 472; h) C.-S. Yan, Y. Peng, X.-B. Xu, Y.-W. Wang, Chem. Eur. J. 2012, 18, 6039; i) X. Yu, T. Yang, S. Wang, H. Xu, H. Gong, Org. Lett. 2011, 13, 2138.

[11] A. García-Domínguez, Z. Li, C. Nevado, J. Am. Chem. Soc. 2017, 139, 6835.

[12] For examples using TDAE in nickel-catalyzed reductive couplings: a) L. Anka-Lufford, K. M M. Huihui, N. J. Gower, L. K. G. Ackerman, D. J. Weix, Chem. Eur. J. 2016, 22, 11564. b) M. Kuroboshi, M. Tanaka, S. Kishimoto, K. Goto, M. Mochizuki, H. Tanaka, Tetrahedron Lett. 2000, 41, 81; c) J. Broggi, T. Terme, P. Vanelle, Angew. Chem. Int. Ed. 2014, 53, 384; d) N. Suzuki, J. L. Hofstra, K. E. Poremba, S. E. Reisman, Org. Lett. 2017, 19, 2150.

[13] a) M. Newcomb, M. A. Filipkowski, C. C. Johnson, Tetrahedron Lett. 1995, 36, 3643; b) H. Fischer, L. Radon, Angew. Chem. Int. Ed. 2001, 40, 1340; c) C. Walling, A. Cioffari, $J$. Am. Chem. Soc. 1972, 94, 6059.

[14] For examples using nickel as radical initator, see a) A. Studer, D. P. Curran, Angew. Chem. Int. Ed. 2016, 55, 58; b) B. Zhang, A. Studer Org. Lett. 2014, 16, 3990; c) A. Leblanc, E. Grau, J.-P. Broyer, C. Boisson, R. Spitz, V. Monteil, Macromolecules 2011, 44, 3293.

[15] For a related mechanistic proposal, see: $S$ Biswax, D. J. Weix, J. Am. Chem. Soc. 2013, 135, 16192.

[16] For DFT studies showing the favored addition of benzyl radicals to Ni(0): O. Gutierrez, J. C. Tellis, D. N. Primer, G. A. Molander, M. C. Kozlowski, J. Am. Chem. Soc. 2015, 137, 4896. 